\title{
21 Eight tons of lifestyle
}

\section{Monitoring a sustainable material footprint for households in Germany and the world}

\author{
Jens Teubler, Sebastian Schuster, \\ and Christa Liedtke
}

\section{Background}

The Sustainable Development Goals (SDGs) emphasise the fact that the use of natural resources is directly linked to the household consumption of products and services (Goal 12: Responsible Consumption and Production) (United Nations General Assembly 2015). Its indicator Material Footprint measures the use and extraction of raw materials in an economy and is therefore compatible with similar indicators on the micro-economic level of households.

Lettenmeier and colleagues (Lettenmeier 2018; Lettenmeier, Liedtke \& Rohn 2014) based their Material Footprint on the MIPS method, a concept that was developed in the early 1990s at the Wuppertal Institut (Liedtke et al. 2014; Schmidt-Bleek 2000) and has since been further developed and applied in several studies (e.g. recently in Buhl, Liedtke, Teubler, Bienge \& Schmidt 2018; Teubler, Buhl, Lettenmeier, Greiff \& Liedtke 2018).

It could be shown that 8 tonnes per person and year are consistent with sustainable use of natural resources by households and therefore consistent with the SDG 12 goal for sustainable consumption. This 8-tonne lifestyle is achievable by most, if not all, households at the global level (Greiff, Teubler, Baedeker, Liedtke \& Rohn 2017; Lettenmeier, Hirvilammi, Laakso, Lähteenoja \& Aalto 2012).

However, sustainable consumption policies affect households differently, in particular when they are confronted with limitations on income, time or freedom of movement (e.g. driving to work). And although it is possible to assess either the average or individual material footprint (per capita or via surveys), we lack methods to describe different types of households, their lifestyles and footprints in a representative manner.

We explore possibilities to do so in this article. Our interest lies in finding an applicable method that allows us to describe the footprint of households regarding their socio-demographic characteristics but also find the causes consumption behaviour. This type of monitoring would enable us to tailor policies for sustainable consumption that respect people's needs and restrictions. 
It would enable us to:

a rank such policies by the size of their effect and costs;

b understand and estimate the effects of financial incentives for sustainable products;

c map the effects of digitalisation;

$\mathrm{d}$ anticipate social fairness issues regarding additional fees of practices and or bans of products and specific services;

e approach household predominantly that show a high ability and willingness to change their lifestyle: and

f address households with high incomes, high environmental awareness and high footprints.

The authors (and others) conducted several studies regarding average footprints in Germany as well as the footprints of individuals. We use these studies as a starting point to develop a solution.

\section{Previous studies and their limitations}

A study in 2017 (Buhl, Teubler, Liedtke \& Stadler 2017) used aggregated macroeconomic resource-intensities (resource use per Euro spent) and combined them with microdata on the income and expenditures of households in the German federal State of North-Rhine Westphalia over three (3) periods (survey carried out every 5 years: 2003, 2008, 2013). While the authors found that the overall or average MF did not change that much over ten years (about 31 tons per person in 2013), the data showed a clear shift from resource use in transport, food and housing towards housing, energy and communication ${ }^{1}$ in particular. Due to the nature of the method applied (resource intensities based on input-/output modelling), it could not be further investigated to what extent changes in lifestyles or the society itself are responsible for these changes (although the strong link between income and environmental pressure could be ascertained). More importantly, it could not be investigated how individual lifestyle choices (e.g. vegetarian or car-free lifestyles) would affect these results.

Several studies have now been conducted at the household and individual lifestyle levels to methodically differentiate behavioural data and footprints (Buhl 2014; Buhl \& Acosta 2015; Greiff et al. 2017; Lähteenoja, Lettenmeier \& Kotakorpi 2008; Lettenmeier et al. 2012). The overall consumption fields were considered, as were individual areas such as sport and time use. Following these studies, an online calculator (www.ressourcen-rechner.de) was created, which has been collecting material footprints and socio-economic data since 2015. The researchers combined online surveys or diaries from either small or large random samples with specific characterisation factors. Thus it was possible to match not only socio-economic data, but also socio-demographic data and voluntary information on, for example, willingness to pay or attitudes towards the environment 
Table 21.1 Variable importance of predictors and performance of linear and non-linear predictions

\begin{tabular}{lll}
\hline Variable Importance & GLM (\%) & MARS (\%) \\
\hline Household size (no.) & 100 & 71 \\
Trips local train (km) & 88.98 & 89 \\
Trips car (km) & 80.85 & 100 \\
Dwelling size (m ${ }^{2}$ ) & 66.23 & 57 \\
Car age (a) & 49.06 & 78 \\
Cars in household (no.) & 48.44 & 78 \\
Trips long-distance train (km) & 46.34 & 52 \\
Travel by long-distance train & 45.11 & 40 \\
Conventional electricity (ref. eco) & 36.81 & 28 \\
Gas car (l/100 km) & 34.68 & \\
Travels car (km) & 29.24 & \\
Holiday long-distance train (h) & 26.04 & \\
Holiday flight (h) & 24.86 & \\
Night storage heating (ref. oil) & 22.28 & \\
Car drivers (no.) & 21.97 & \\
Milk (no. cups 200 ml) & 20.62 & \\
Consumption electricity (kWh) & 19.27 & \\
Holidays luxury hotel (d) & 18.45 & \\
Car passenger > 2 (ref. alone) & 18.31 & \\
Electricity source IDK (ref. eco) & 18.09 & \\
Holidays car (km) & 16.81 & 0.60 \\
Meat consumption high (ref. vegan) & 10.27 & \\
RMSE & 0.48 & \\
R ${ }^{2}$ & 0.74 & \\
\hline
\end{tabular}

Source: Buhl et al. (2019)

Note: Variable importance measures the relative decrease in prediction error (MSE \& RMSE) with the most important predictor scaled to 100 . The importance of categorical items in relation to a reference (ref.). 'Electricity source IDK' is electricity source not known ('I don't know'). RMSE is the rooted mean squared error. $\mathrm{R}^{2}$ measures the accuracy of the prediction.

to the corresponding resource use from lifestyle choices (see e.g. Buhl, Liedtke \& Bienge 2017; Buhl et al. 2018; Buhl, Liedtke, Teubler, Schuster \& Bienge 2019).

Table 21.1 shows an example from an online survey with over 60,000 users that investigates the predictors for resource use. While the sample is biased (over-representation of, for example, female vegetarians), the online tool ${ }^{2}$ and its set of consumption questions could be used to identify the consumption choices that matter the most. Here, household size, mobility choices and energy use already account for more than $70 \%$ of the overall footprints. Reducing the number of questions offers two major advantages. First, it enables the researcher to conduct surveys in a time-efficient manner that allows for integration of additional lifestyle-related questions. Secondly, it highlights the areas where a high level of differentiation of consumption choices is highly relevant for the resulting footprint. As a result, a persons' footprint can be estimated on the basis of less information but still with adequate precision. 


\section{Challenges and solution}

The two different approaches can be classified as top-down and bottom-up modelling of Material Footprints (or any other environmental impact indicator for that matter). Top-down methods heavily rely on information from macroeconomic tables (usually input-output tables for trade that transform monetary into physical flows). Bottom-up approaches, on the other hand, are often interchangeable with calculations from life cycle assessments (focusing on the function and services of products or products themselves to satisfy needs).

The third possible method for providing relevant and comprehensive environmental data are so-called hybrid approaches, where top-down data is further differentiated with the help of bottom-up modelling. While this solution is promising, in regard to the calculation of a comprehensive average footprint in particular countries, it still does not provide the necessary sociodemographic information to explain which and why households exhibit their individual footprint.

We believe that this gap between footprints per capita (equalising consumption over a large population) and footprints per individuum (with usually highly biased or random samples) can be bridged in other ways. We suggest using a probability based access panel of consumers to achieve both goals: differentiation of consumption and lifestyle choice where it matters the most (especially regarding needs, preferences and restrictions) as well as providing a comprehensive picture of the society and its material footprint.

This type of research design includes a random selection of individuals within a statistical population, observations of the same variables over short or long periods of time and weighting procedures to deal with, for example, non-responses.

This would enable us to corroborate findings from previous studies. It also helps to investigate more deeply how footprints are affected by sociodemographic characteristics like household income, gender or employment status. More importantly, it would allow researchers to link environmental footprints to individual driving forces like needs, parenthood, life satisfaction and opinions or, for example, the willingness to pay for sustainable products (see Figure 21.1 for examples of potential factors that could be investigated).

\section{Advantages of the approach}

A panel solution offers several advantages. First, panels exist over a long time with only small changes. The socio-economic and socio-demographic data can, therefore, be used for more than one study. This allows to link data from previous studies with the current Footprint survey to identify additional relevant parameters or to validate results. One example for this would be the impact of so-called critical life events (e.g. unemployment, illness but also marriage and children) on a person's consumption behaviour and one's footprint. 


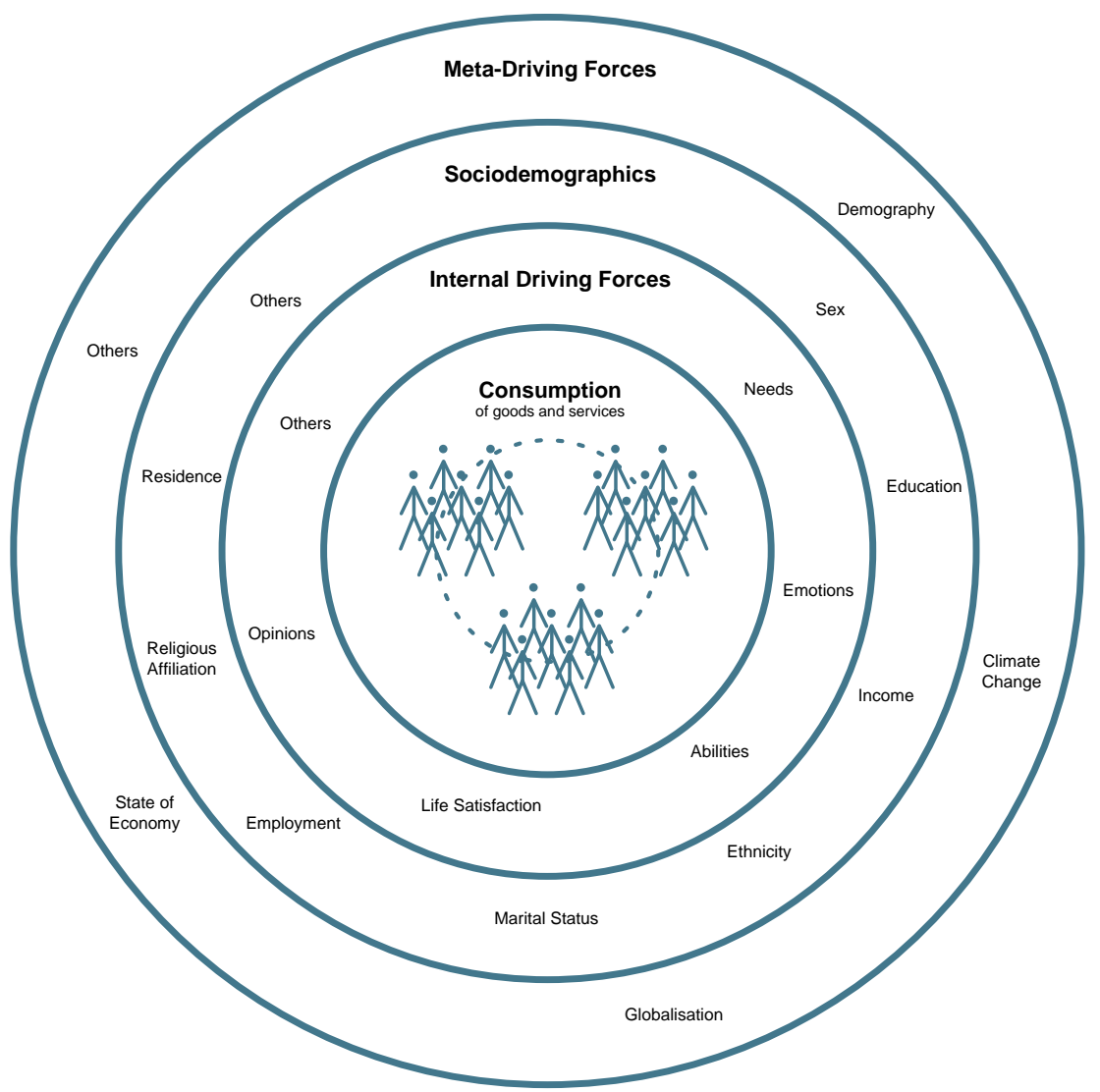

Figure 21.1 Household groups and potential driving forces for sustainable consumption (to be further investigated).

Source: own compilation.

The second advantage stems from the ability of researchers to weight groups in the sample that are over- or underrepresented from either the sampling design itself or from, for example, deviations from nonresponses. By using state-of-art methods, the results of the sample can be re-distributed to reflect the society it represents (see Gabler, Kolb, Sand \& Zins 2015 for a short overview on approaches and literature). Thus, not only average footprints for the overall society can be calculated but also for parts of the society that fulfil specific characteristics (sex, income, education, age, among others).

A further benefit of using a panel is its usage for trend and foresight analysis. If conducted yearly, trends of consumption can be shown. Therefore, studies over several years could reveal the reactions of households to events or policies in a robust and transparent way. 
From the point of view of survey design, such an approach also enables researchers to learn from follow-up surveys. Since it is known whether a household participated the last time and what its responses were, additional questions could investigate more deeply into issues of interest. If, for example, the footprint of car-owners correlates with large footprints, it could be interesting to know if this trend is even more pronounced with the owners of SUVs.

Outside of the traditional survey methods, this approach could also be combined with the increasingly large digital data pools. Big data and App data, if collected with the knowledge and approval of participants, can answer research questions in real-time and mirror them to the actors in politics and society but also the participants themselves. The usage of GPS data, for example, collected by the smartphones of participants, could map movements and mobility choices, giving insights into the cause-effect chains of the environmental footprint of our day-to-day travel.

This integration of digital data also makes it possible to integrate statistics and research on the use of time. Since people use their time to realise their personal goals and needs, it is often more directly linked to the environmental impact of consumption then expenses. Time prosperity is already a relevant topic for many groups in our society, especially for the younger generation (Buhl, Schipperges \& Liedtke 2017). Transformation research, in particular for enabling sustainable consumption, can thus generate a higher social and political impact.

\section{Data requirements for environmental data}

The matching data on the environmental side of such a panel study can be provided efficiently. Using generic life cycle inventories allows for bottom-up models of consumption choices that are robust enough for overall results (see Teubler et al. 2018; Wiesen, Mathieu Saurat \& Michael Lettenmeier 2014; Wiesen \& Wirges 2017 for examples). These results can be further differentiated in light of specific research questions. If, for example, watching television is relevant for both time and resource use, it could be beneficial to model characterisation factors for different types of television sets and request information of the participants to that effect.

The limit of this type of modelling lies in its ability to account for all the consumption areas that have a low specific effect, but still, have a relevant share in the overall footprint if combined. These are often also areas where a survey would require many questions (thus time) without affecting the results to a high degree (e.g. ownership of small electrical devices or tools).

One solution for this data gap might be the calculation of a baseline of material footprint. This baseline is attributed to every panel participant regarding basic parameters such as household size or level of income. It could be based on environmental data from macroeconomic studies (e.g. resource intensities) as well as previous bottom-up studies. Although it would not be possible to account for $100 \%$ of the overall footprint of an average household, 
the authors are confident that this approach would cover most, if not all relevant areas of sustainable consumption.

\section{Outlook (pilot study)}

A change in the analytical focus is needed to achieve the objectives of SDG 12 and successfully implement various programmes such as ProgRess and the National Programme on Sustainable Consumption in Germany. Rather than reporting on the average Material Footprint in a country alone, monitoring should include information on modern lifestyles and the specific social situations people find themselves in. The ongoing discussion on $\mathrm{CO}_{2}$ taxation in Germany is a good example of this requirement. We do not know, as of yet, what groups in our society would benefit from it and which low-income groups would be affected by it without having reasonable options to reduce their overall fossil fuel use.

A more differentiated monitoring could, therefore, help to identify socially inclusive approaches to climate protection (and sustainable resource use overall). It is crucial in our opinion, to devise sustainability policies that distribute the burdens and benefits fairly and ecologically in terms of household budgets and quality of life.

The next step is to plan and conduct a pilot study to test the hypotheses of the authors. Applying the learnings from previous studies (in particular Buhl et al. 2019 and Teubler et al. 2018), a first set of material footprint questions has to be selected that:

- $\quad$ predict most of the material footprint;

- $\quad$ are relevant in regard to current; and

- discuss policies in Germany such as Energiewende (shift towards renewable energies), low-carbon transport or Carbon Tax, can be answered by households without much effort or additional information.

A second group of questions will be then used to match the results with needs, preferences and restrictions of households. They should cover areas like life satisfaction, personality disposition or lifestyles (using, for example, a tool by Gunnar Otte (Otte 2004) that combines several social milieu models with the theory of Pierre Bourdieu).

The calculation of characterisation factors for life-cycle raw material and natural resource use should include both questions and the material footprint of the baseline of 'other and general services'. The survey can then be conducted using an already existing panel (for example the GESIS panel ${ }^{3}$ ), applying state-of-art methods for sampling and weighting.

Finally, results are investigated with the help of multivariate statistical methods (for example regression models, cluster analysis, factor analysis and latent class analysis), but should also be compared to the results of previous studies. Does the weighted average provide results in the range of 
macro-economic statistics? Are we able to differentiate between the soft characteristics of households and their footprints? Are there any unambiguous differences between households in urban and rural areas, that have not been taken into account in former studies? Can we replicate, corroborate or falsify findings from smaller random samples? Do we find 'black spots' of household groups that are overwhelmingly underrepresented in the panel? Does the material footprint composition differ significantly between different ethnicities? And are we able to design a similar study that explains the potential effects of a specific policy for sustainable consumption?

\section{Discussion}

We have presented a feasible solution for the monitoring of the resource use of households. A solution that, if successful, could be used to test and quantify the effects of explicit measures for lowering the Material Footprint of consumption. Subsequently, it also measures the Material Footprint of the products consumed or the services they provide.

The methodological approach, therefore, addresses central fields for a transformation towards more sustainable consumption: consumption patterns, lifestyles and policies, but also innovative products, processes and business models. It helps to evaluate the sustainability of innovations during the development of product-service systems. The latter is of great importance for sustainability, as many unintended side effects are usually not evaluated during their development (especially innovations based on digital services).

The approach provides numerous applications for sustainability research in the long run. It could, for example, provide insights on the success of nudging policies or on time budgets for households and their relationship with social milieus in a digitalised world. It would certainly facilitate investigations into problem shifts of consumption (indirect rebound effects), because the results are not only differentiated on a socio-economic level. And it could enable producers and software developers with information on how and why households consume the way they are. ${ }^{4}$

This can be achieved using a survey design focused on a panel, and by differentiating along several dimensions. The social dimension allows for the differentiation of societal groups, their preferences, limitations and characteristics. The second dimension, the environmental impacts, is then further differentiated into different areas of consumption (or across those areas to identify potential rebounds). This would provide researchers, policymakers, companies and households alike with the necessary information to steer sustainable consumption fairly and effectively. As such and since it is not restricted to the Material Footprint as a single indicator, a panel approach could also be used to help companies developing sustainable products and services (SDG 12.6). It could raise awareness for sustainable development 
(SDG 12.8), identify pressure factors of climate change (SDG 13) or reveal inequalities (SDG 10).

The aim is to achieve a high quality of life for the various lifestyle groups within our ecological boundaries - provided that there is a balance between social and individual development opportunities. The approach described here would be the first step for that.

\section{Abbreviations}

GLM generalised linear regression model

MARS multivariate adaptive regression splines

MIPS material input per service

MSE mean squared error

RMSE rooted mean squared error

SDG Sustainable Development Goals

\section{Notes}

1 It is reasonable to assume that this shift towards communication is a direct result of digitalisation.

2 See www.ressourcen-rechner.de.

3 See www.gesis.org/gesis-panel/gesis-panel-home.

4 A current study on the 'Latest initiatives by science and policy to promote sustainable consumption and recommendations to enhance the German Sustainability Strategy'. discusses some of these applications and summarises the scientific discourse on sustainable consumption in Germany. It is expected to be published by the end of 2019 .

\section{References}

Buhl, J. (2014). Revisiting Rebound Effects from Material Resource Use. Indications for Germany Considering Social Heterogeneity. Resources, 3(1), 106-122.

Buhl, J. and Acosta, J. (2015). Work Less, Do Less?: Working Time Reductions and Rebound Effects. Sustainability Science. Retrieved 9 November 2015 from http://link. springer.com/10.1007/s11625-015-0322-8.

Buhl, J., Liedtke, C., and Bienge, K. (2017). How Much Environment Do Humans Need? Evidence from an Integrated Online User Application Linking Natural Resource Use and Subjective Well-Being in Germany. Resources, 6(4), 67.

Buhl, J., Liedtke, C., Teubler, J., Bienge, K., and Schmidt, N. (2018). Measure or Management? - Resource Use Indicators for Policymakers Based on Microdata by Households. Sustainability, 10(12), 4467.

Buhl, J., Liedtke, C., Teubler, J., Schuster, S., and Bienge, K. (2019). A Material Footprint Model for Green Information Systems - Using Statistical Learning to Identify the Predictors of Natural Resource Use. Cogent Engineering, 6(1). Retrieved 4 June 2019 from www.cogentoa.com/article/10.1080/23311916.2019.1616655.

Buhl, J., Schipperges, M., and Liedtke, C. (2017). Die Ressourcenintensität der Zeit und ihre Bedeutung für nachhaltige Lebensstile. Verbraucherwissenschaften (pp. 295-311). Berlin: Springer. 
Buhl, J., Teubler, J., Liedtke, C., and Stadler, K. (2017). Der Ressourcenverbrauch privater Haushalte in NRW. uwf UmweltWirtschaftsForum | Sustainability Management Forum, 25, 255-264.

Gabler, S., Kolb, J.-P., Sand, M., and Zins, S. (2015). Gewichtung. SDM-Survey Guidelines (GESIS Leibniz Institute for the Social Sciences). Retrieved 13 September 2019 from www. gesis.org/gesis-survey-guidelines/statistics/gewichtung/.

Greiff, K., Teubler, J., Baedeker, C., Liedtke, C., and Rohn, H. (2017). Material and Carbon Footprint of Household Activities. In D. V. Keyson, O. Guerra-Santin and D. Lockton (Eds.), Living Labs: Design and Assessment of Sustainable Living (pp. 259-275). Cham: Springer International Publishing.

Lähteenoja, S., Lettenmeier, M., and Kotakorpi, E. (2008). The Ecological Rucksack of Households: Huge Differences, Huge Potential for Reduction? (pp. 319-337). Retrieved from http://epub.wupperinst.org/frontdoor/index/index/docId/2937.

Lettenmeier, M. (2018). A Sustainable Level of Material Footprint - Benchmark for Designing One-Planet Lifestyles [Materiaalijalanjäljen kestävä taso -mittapuu yhden planeetan elämäntapojen toteuttamiseen]. Aalto University. Retrieved from https://aaltodoc.aalto.fi/ handle/123456789/31300.

Lettenmeier, M., Hirvilammi, T., Laakso, S., Lähteenoja, S., and Aalto, K. (2012). Material Footprint of Low-Income Households in Finland - Consequences for the Sustainability Debate. Sustainability, 4(12), 1426-1447.

Lettenmeier, M., Liedtke, C., and Rohn, H. (2014). Eight Tons of Material Footprint Suggestion for a Resource Cap for Household Consumption in Finland. Resources, 3(3), $488-515$.

Liedtke, C., Bienge, K., Wiesen, K., Teubler, J., Greiff, K., Lettenmeier, M., and Rohn, H. (2014). Resource Use in the Production and Consumption System - The MIPS Approach. Resources, 3(3), 544-574.

Otte, G. (2004). Sozialstrukturanalysen mit Lebensstilen. Wiesbaden: VS Verlag für Sozialwissenschaften. Retrieved 5 August 2019, from http://link.springer.com/10.1007/ 978-3-322-99335-9.

Schmidt-Bleek, F. (2000). Das MIPS-Konzept: weniger Naturverbrauch - mehr Lebensqualität durch Faktor 10. München: Droemer Knaur.

Teubler, J., Buhl, J., Lettenmeier, M., Greiff, K., and Liedtke, C. (2018). A Household's Burden-The Embodied Resource Use of Household Equipment in Germany. Ecological Economics, 146, 96-105.

United Nations General Assembly. (2015). Transforming Our World: The 2030 Agenda for Sustainable Development. United Nations. Retrieved 30 March 2016 from www.un. $\mathrm{org} / \mathrm{ga} / \mathrm{search} /$ view_doc.asp?symbol=A/RES/70/1\&Lang=E.

Wiesen, K., Mathieu Saurat and Michael Lettenmeier. (2014). Calculating the Material Input per Service Unit using the Ecoinvent Database. International Journal of Performability Engineering, 10(4), 357-366.

Wiesen, K. and Wirges, M. (2017). From Cumulated Energy Demand to Cumulated Raw Material Demand: The Material Footprint as a Sum Parameter in Life Cycle Assessment. Energy, Sustainability and Society, 7(1), 13. 